\title{
Monogenic Dominant Resistance to Gummy Stem Blight in Two Melon (Cucumis melo) Accessions
}

\author{
T. L. Zuniga, Graduate Research Assistant, Department of Plant Pathology, J. P. Jantz, Research Support Special- \\ ist, Department of Plant Breeding, T. A. Zitter, Professor, Department of Plant Pathology, and M. K. Jahn, Asso- \\ ciate Professor, Department of Plant Breeding, Cornell University, Ithaca, NY 14853
}

\begin{abstract}
Zuniga, T. L., Jantz, J. P., Zitter, T. A., and Jahn, M. K. 1999. Monogenic dominant resistance to gummy stem blight in two melon (Cucumis melo) accessions. Plant Dis. 83:1105-1107.

Two melon (Cucumis melo L.) accessions, plant introduction (PI) 157082 and PI 511890, reported to be resistant to gummy stem blight, a disease incited by the fungus Didymella bryoniae, were crossed with a susceptible parent to determine the inheritance of resistance. Resistance in both accessions is due to a single dominant gene, based on analysis of $F_{1}, F_{2}$, and backcross populations. Additionally, PI 157082 was crossed with PI 140471, the other source of resistance identified to date, to examine the genetic relationship of resistance found in these two sources. The frequency of susceptible individuals from the (PI $157082 \times 140471) F_{2}$ population was consistent with a 15:1 resistant:susceptible ratio, indicating that PIs 140471 and 157082 possess different resistance genes.
\end{abstract}

Additional keywords: cucurbits, disease resistance

Gummy stem blight (GSB) of cucurbits is incited by the fungus Didymella bryoniae (Auersw.) Rehm (synonyms: Mycosphaerella citrullina (C. O. Sm.) Gross. and M. melonis (Pass.) Chiu \& J. C. Walker) and its anamorph Phoma cucurbitacearum (Fr.:Fr.) Sacc. (synonyms: Ascochyta cucumis Fautrey \& Roum. and A. citrullina (F. Chester) C. O. Sm.) (13). The disease is most common in tropical and sub-tropical areas of the world, but it is also a serious disease of cucurbits in the United States (15). In the southeastern states, GSB is the most destructive disease of watermelon (Citrullus lanatus) and cucumber (Cucumis sativus), $(1,18)$ and also causes serious losses on melon (C. melo). The disease has increased in importance in recent years as effective chemical and genetic control of other cucurbit diseases has become available (14).

Symptoms of GSB include circular, tan to dark-brown spots on leaves that may

Corresponding author: M. K. Jahn

E-mail:mmk9@cornell.edu

Support for this work was provided by a grant from the Permanent Research Fund of the American Seed Research Foundation, a subcontract from Michigan State University USAID Agricultural Biotechnology for Sustainable Productivity to M. K. Jahn, and funds allocated by the New York State College of Agriculture and Life Sciences for Hatch Project NYC 153-417 (T. A. Zitter) and NYC 149-486 (M. K. Jahn).

Accepted for publication 20 August 1999.

Publication no. D-1999-0929-01R

(C) 1999 The American Phytopathological Society enlarge under favorable conditions to cover the leaf. On cotyledons and stems of young plants, circular black or tan lesions may be evident. Water-soaked areas may develop on hypocotyls and leaves. Cankers may appear in stem cortical tissue that produce a typical brown, gummy exudate and may girdle the stem, resulting in plant death (14).

Control practices include the use of fungicide-treated seed and a minimum 2-year crop rotation (15). Although satisfactory chemical control can be achieved with fungicides (1), resistance to benzimidazole products has been reported $(2,4,5,15)$. Several sources of GSB resistance in wild $C$. melo accessions from the United States Department of Agriculture (USDA) National Plant Germplasm System (NPGS) have been previously reported $(6,16,17,20)$. A recent study that employed both greenhouse and field evaluations yielded several new sources of resistance to GSB among the 800 accessions examined. Levels of resistance identified in this study were equal to or greater than any previously reported (20). Although genetic resistance was identified in C. melo in the 1960s and efforts to incorporate resistance into cultivated melon have been ongoing (7-10), no commercial varieties with adequate levels of resistance are currently available (15). Thus, there is still a need to incorporate higher levels of genetic resistance in melon varieties.

The first objective of this study was to determine the mode of inheritance of GSB resistance found in two highly resistant $C$. melo plant introductions (PI), USDA PIs 157082 and 511890 , identified by Zhang et al. (20). The second objective was to determine the genetic relationship between these sources of resistance and PI 140471, a wild melon previously described as having GSB resistance (17) controlled by a single dominant gene (12). Due to problems with producing seed of the necessary crosses with PI 511890, only the relationship between PI 157082 and PI 140471 was determined in this study.

\section{MATERIALS AND METHODS}

Germ plasm and population development. C. melo PI 157082 and PI 511890 obtained from the USDA NPGS at Ames, Iowa were crossed with a susceptible genotype, 'Cornell ZPPM 339', with each other, and with PI 140471, to determine the mode of inheritance of GSB resistance. Cv. Cornell ZPPM 339 is a cantaloupe breeding line, well-adapted to greenhouse and field conditions, and monoecious, which eliminates the need for emasculation when used as a female parent. Controlled pollinations were carried out in the field and greenhouse to generate reciprocal $F_{1}, F_{2}$, and backcross $(\mathrm{BC})$ progenies. Due to poor adaptation of PI 511890 to conditions in Ithaca, New York and extreme susceptibility to powdery mildew, we were unable to produce adequate seed for testing from PI $157082 \times$ PI 511890 and reciprocal crosses and PI $511890 \times$ PI 140471 and reciprocal crosses in either the greenhouse or the field. To confirm previously published results regarding genetics of resistance for PI 140471, we also crossed PI 140471 with the cv. Mainstream, released by the United States Vegetable Laboratory in Charleston, South Carolina (11) and developed reciprocal $\mathrm{F}_{1}, \mathrm{~F}_{2}$, and $\mathrm{BC}$ progenies. Cv. Mainstream was bred under unprotected conditions in South Carolina, and some tolerance to the disease is observed under some field conditions, but it is rated susceptible in inoculated tests (20).

For field plantings in Ithaca, New York, 4-week-old seedlings from the greenhouse were acclimated for 3 days in cold frames outside the greenhouse before transplanting to beds covered with black plastic mulch. Plots consisted of 12 plants, with 2 plants per hill. Rows were spaced $2.1 \mathrm{~m}$ apart and hills were $0.6 \mathrm{~m}$ apart within the rows. Prior to transplanting, field plots were plowed and disked once, then broadcast fertilized with $225 \mathrm{Kg}$ of 10-20-20 fertilizer. At transplant, approximately $500 \mathrm{ml}$ 
of a starter fertilizer (9-45-15) was applied at a rate of $7 \mathrm{~g} /$ liter for each hill.

Resistance evaluations. To assure uniform stands for resistance evaluations, seeds were germinated on paper towels held at $28^{\circ} \mathrm{C}$ for $48 \mathrm{~h}$, and seedlings were transplanted to Todd planter flats ( 4 by 8 cells; Hummert International, Earth City, MO) filled with Peatlite mix (1:1 peat moss:vermiculite). Two susceptible control plants each of 'Top Mark' and 'Honeydew Greenflesh' were planted randomly in each flat to monitor inoculation efficacy and test severity. Seedlings were held in a greenhouse at $24^{\circ} \mathrm{C}$. All evaluations for genetic studies were carried out in the greenhouse essentially as described by Zhang et al. (20) using NY1, a highly virulent $D$. bryoniae isolate collected in the field in Onondaga, New York (3).

Data collection and analyses. Disease severity on stems of individual plants was recorded using a modified version of the procedure by Zhang et al. (20). Instead of a single reading at 7 days after inoculation, a second reading was also made at 21 days after inoculation. A 1 to 5 scale was used where $1=$ no damage; $2=$ a single lesion 1 to $10 \mathrm{~mm}$ long or coalesced lesions 1 to 20 $\mathrm{mm}$, no girdling; $3=$ lesions 21 to $80 \mathrm{~mm}$, girdling of the stem, or both; $4=$ withered stem; and $5=$ dead seedling (19). The numbers of individuals falling into resistant and susceptible classes were tallied, and observed segregation ratios in $\mathrm{F}_{2}$ and $\mathrm{BC}$ populations were tested for goodnessof-fit using the chi-square statistic.

\section{RESULTS}

Parental reactions. Disease scores for parental lines inoculated with the GSB pathogen are summarized in Table 1. There was a clear and consistent difference in stem disease ratings at 21 days after inoculation between the resistant and susceptible parents in all tests. This defined the categories which were then used to group individuals from segregating populations. All plants of the resistant parents showed disease scores of 1 or 2 . Almost all (96\%) plants of PI $140471,75 \%$ of PI 157082, and $70 \%$ of PI 511890 had scores of 1 . The susceptible parent ZPPM 339 showed only disease scores between 3 and

Table 1. Stem disease severity scores for melon genotypes used as parents in this study 21 days after inoculation with Didymella bryoniae

\begin{tabular}{lcl}
\hline Parents & Disease index $^{\mathbf{a}}$ & Rating \\
\hline ZPPM 339 & $4.3( \pm 0.51)$ & Susceptible \\
PI 140471 & $1.1( \pm 0.20)$ & Resistant \\
PI 157082 & $1.3( \pm 0.57)$ & Resistant \\
PI 511890 & $1.3( \pm 0.47)$ & Resistant \\
\hline
\end{tabular}

a Mean \pm standard deviation of severity scores based on a 1 to 5 scale $(1=$ no damage; $2=\mathrm{a}$ single lesion 1 to $10 \mathrm{~mm}$ long or coalesced lesions 1 to $20 \mathrm{~mm}$, no girdling; $3=$ lesion 21 to $80 \mathrm{~mm}$, girdling of the stem, or both; $4=$ withered stem; and $5=$ dead seedling).
5 (Table 1); $97 \%$ of these seedlings had either withered stems or were dead (scores

Inheritance of resistance in PI 157082. The reciprocal $F_{1}$ progenies between PI 157082 and ZPPM 339 showed uniformly high resistance, indistinguishable from the resistant parent, and consistent with dominant inheritance with no cytoplasmic lation segregated consistent with a 3:1 resistant:susceptible ratio (Table 2), supporting the hypothesis that resistance in this PI is controlled by a single dominant gene. Plants from the $\mathrm{BC}$ population derived from the resistant parent were uniformly resistant, and the $\mathrm{BC}$ derived from the susceptible parent segregated consistent with a 1:1 resistant:susceptible ratio (Table 2 ), which further supports monogenic dominant inheritance of gummy stem blight resistance from PI 157082.

Relationship of dominant resistance from PI 157082 to the $M c$ gene from PI 140471. To determine whether the dominant resistance allele in PI 157082 is related to the $M c$ locus previously identified by Prasad and Norton (12), PI 157082 was crossed with PI 140471. We first confirmed that PI 140471 indeed carries a single dominant gene by producing and screening $\mathrm{F}_{1}, \mathrm{~F}_{2}$, and resistant and susceptible $\mathrm{BC}$ progenies with $C$. melo cv. Mainstream (data not shown). All plants from the $F_{1}$ population obtained by crossing PI 140471 and PI 157082 were uniformly highly resistant, with disease scores of 1 (Table 2). The $F_{2}$ plants segregated consistent with a 15:1 resistant:susceptible ratio (Table 2), supporting the hypothesis that GSB resistance in PI 157082 is controlled by a resistance allele at a locus that is unlinked to the $M c$ locus. Moreover, most of the plants in the susceptible category were dead $(60 \%)$ or had severe stem infections $(26 \%)$, while of 4 and 5). (maternal) factors involved. The $\mathrm{F}_{2}$ popu-

the majority (67\%) of the resistant $\mathrm{F}_{2}$ plants had scores of 1 .

Inheritance of resistance in PI 511890. Reciprocal $F_{1}$ populations of PI 511890 and ZPPM 339 were highly resistant and their reactions did not differ, suggesting that GSB resistance from this source is also dominant, and that no cytoplasmic (maternal) factors are involved in its expression. $F_{2}$ plants segregated consistent with a 3:1 resistant:susceptible ratio (Table 2 ), indicating this source also possesses monogenic dominant resistance to GSB As expected under this hypothesis, plants from the resistant $\mathrm{BC}$ were uniformly resistant, while those from the susceptible BC segregated consistent with a 1:1 resistant:susceptible ratio (Table 2).

\section{DISCUSSION}

Previously, a single dominant gene $(M c)$ in PI 140471 was reported (12) and has been used in the development of several varieties and breeding lines (7-10). In a recent study, however, releases originating from PI 140471 showed intermediate resistance or were rated as susceptible in greenhouse and field screens (20). Zhang et al. (20) suggested that this failure to recover parental levels of resistance in cultivated breeding types might be the result of interactions of the $M c$ gene with different genetic backgrounds. Alternatively, the resistance conferred by this gene may not be sufficiently high to protect vines that are under extreme physiological stress due to the concentrated set of large fruit (20).

Results from our genetic studies, using a different susceptible parent and a very reliable, severe screening method, confirmed the previous report of a single gene conferring resistance to GSB in PI 140471 (data not shown). Similarly, GSB resistance in PIs 157082 and 511890 also appears to be controlled by a single dominant

Table 2. Response of Cucumis melo parental genotypes and intercrossed populations to inoculation with Didymella bryoniae

\begin{tabular}{lcrrrr}
\hline & & \multicolumn{2}{c}{ Number of plants } & & \\
\cline { 2 - 3 } Pedigree $^{\mathbf{b}}$ & Generation $^{\mathbf{c}}$ & $\mathbf{R}$ & $\mathbf{S}$ & Expected ratio (R:S) & $\mathbf{P}_{\alpha=\mathbf{0 . 0 5}}$ \\
\hline $\mathrm{ZM}$ & $\mathrm{P}$ & 1 & 30 & $0: 1$ & $\ldots$ \\
471 & $\mathrm{P}$ & 24 & 0 & $1: 0$ & $\ldots$ \\
082 & $\mathrm{P}$ & 20 & 0 & $1: 0$ & $\ldots$ \\
890 & $\mathrm{P}$ & 26 & 0 & $1: 0$ & $\ldots$ \\
$082 \times \mathrm{ZM}$ & $\mathrm{F}_{1}$ & 31 & 4 & $1: 0$ & $\ldots$ \\
$\mathrm{ZM} \times 082$ & $\mathrm{~F}_{1}$ & 14 & 2 & $1: 0$ & $\ldots$ \\
$082 \times \mathrm{ZM}$ & $\mathrm{F}_{2}$ & 84 & 21 & $3: 1$ & 0.31 \\
$(082 \times \mathrm{ZM}) \times \mathrm{ZM}$ & $\mathrm{BC}_{\mathrm{s}}$ & 36 & 35 & $1: 1$ & $\ldots$ \\
$(082 \times \mathrm{ZM}) \times 082$ & $\mathrm{BC}_{\mathrm{r}}$ & 65 & 0 & $1: 0$ & $\ldots$ \\
$890 \times \mathrm{ZM}$ & $\mathrm{F}_{1}$ & 17 & 1 & $1: 0$ & $\ldots$ \\
$\mathrm{ZM} \times 890$ & $\mathrm{~F}_{1}$ & 46 & 1 & $1: 0$ & 0.14 \\
$890 \times \mathrm{ZM}$ & $\mathrm{F}_{2}$ & 63 & 27 & $3: 1$ & 0.15 \\
$(890 \times \mathrm{ZM}) \times \mathrm{ZM}$ & $\mathrm{BC}_{\mathrm{s}}$ & 40 & 27 & $1: 1$ & $\ldots$ \\
$(890 \times \mathrm{ZM}) \times 890$ & $\mathrm{BC}_{\mathrm{r}}$ & 54 & 0 & $1: 0$ & $\ldots$ \\
$471 \times 082$ & $\mathrm{~F}_{1}$ & 8 & 0 & $1: 0$ & 0.13 \\
$471 \times 082$ & $\mathrm{~F}_{2}$ & 234 & 23 & $15: 1$ & \\
\hline $\mathrm{R}$ & & & & & $\ldots$ \\
\hline
\end{tabular}

${ }^{a} \mathrm{R}=$ resistant, $\mathrm{S}=$ susceptible.

b $\mathrm{ZM}=$ ZPPM 339; 471 = PI 140471; 082 = PI 157082; and 890 = PI 511890.

c $\mathrm{P}=$ parent; $\mathrm{BC}_{\mathrm{r}}$ and $\mathrm{BC}_{\mathrm{s}}=$ backcross to resistant and susceptible parents, respectively. 
gene but, due to lack of availability of the necessary populations, we were unable to establish whether these two PIs share the same gene for resistance or contain two distinct resistance genes.

We were, however, able to generate the necessary populations to determine the relationship between the $M c$ locus in PI 140471 and the resistance gene from PI 157082. Our results clearly establish that these two accessions contain distinct resistance genes at unlinked loci. Preliminary results from our breeding program indicate that the combination of these two genes may yield higher levels of resistance than either gene alone (J. P. Jantz and M. K. Jahn, unpublished results).

We have not conducted a survey of $D$. bryoniae isolates on these two new sources of resistance, so we do not know if these genetic resources differ from PI 140471 with regard to fungal isolate specificity. We do know from previous research (3) and from additional studies (T. L. Zuniga and T. A. Zitter, unpublished results) that race-specificity does not exist in cucurbit species including cucumber (19), although one previous report indicated that in melon resistance from PI 140471 may not be consistently expressed in the field (16). When combined in a single genotype, diverse sources of resistance may increase both the level of resistance and the breadth of protection, augmenting chemical disease control approaches which are currently judged inadequate $(1,4)$, especially when environmental conditions are conducive to disease development (1).

\section{ACKNOWLEDGMENTS}

We thank J. Drennan, G. Moriarty, and W. Makepeace for technical support and assistance; and Y. Zhang, A. P. Keinath, and anonymous reviewers for critical review of the manuscript.

\section{LITERATURE CITED}

1. Keinath, A. P. 1995. Fungicide timing for optimum management of gummy stem blight epidemics on watermelon. Plant Dis. 79:354358.

2. Keinath, A. P., Cook, W. P., and DuBose, V. 1992. Control of gummy stem blight in watermelon with fungicides, 1991. Fungic. Nematic. Tests 47:156.

3. Keinath, A. P., Farnham, M. W., and Zitter, T. A. 1995. Morphological, pathological, and genetic differentiation of Didymella bryoniae and Phoma spp. isolated from cucurbits. Phytopathology 85:364-369.

4. Keinath, A. P., and Zitter, T. A. 1995. First report of benomyl-insensitive Didymella bryoniae in the United States. (Abstr.) Phytopathology 85:1126.

5. Keinath, A. P., and Zitter, T. A. 1998. Resistance to benomyl and thiophanate-methyl in Didymella bryoniae from South Carolina and New York. Plant Dis. 82:479-484.

6. McGrath, D. J., Vawdrey, L., and Walker, I. O. 1993. Resistance to gummy stem blight in muskmelon. HortScience 28:930-931.

7. Norton, J. D. 1971. Gulfcoast-A sweet cantaloupe for the produce chain store market. Ala. Agric. Exp. Stn. Leafl. 82.

8. Norton, J. D. 1972. Chilton, a high quality fruit for the commercial market. Ala. Agric. Exp. Stn. Leafl. 84.

9. Norton, J. D., and Cosper, R. D. 1989. Ac-70154 a gummy stem blight-resistant muskmelon breeding line. HortScience 24:709-711.
10. Norton, J. D., Cosper, R. D., Smith, D. A and Rymal, K. S. 1985. Aurora-a high quality disease resistant cantaloupe. Ala. Agric. Exp. Stn. Circ. 278

11. Nugent, P. E., Hoffman, J. C., and Andrus, C. F. 1979. 'Mainstream' melon. HortScience 14:192.

12. Prasad, K., and Norton, J. D. 1967. Inheritance of resistance to Mycosphaerella citrullina in muskmelon. J. Amer. Soc. Hortic. Sci. 91:396-400.

13. Sherf, A. F., and MacNab, A. A. 1986. Pages 340-346 in: Vegetable Diseases and Their Control. Wiley-Interscience, New York.

14. Sitterly, W. R. 1972. Breeding for disease resistance in cucurbits. Annu. Rev. Phytopathol. 10:471-490.

15. Sitterly, R. W., and Keinath, A. P. 1996. Gummy stem blight. Pages 27-28 in: Compendium of Cucurbit Diseases. T. A. Zitter, D. L. Hopkins, and C. Thomas, eds. APS Press, St. Paul, MN.

16. Sowell, G., Jr. 1981. Additional sources of resistance to gummy stem blight of muskmelon. Plant Dis. 65:253-254.

17. Sowell, G., Jr., Prasad, K., and Norton, J. D. 1966. Resistance of Cucumis melo introductions to Mycosphaerella citrullina. Plant Dis. Rep. 50:661-663.

18. St. Amand, P. C., and Wehner, T. C. 1991 Crop loss to 14 diseases of cucumber in North Carolina from 1983 to 1988 . Cucurbit Genet. Coop. Rep. 14:15-17.

19. St. Amand, P. C., and Wehner, T. C. 1995. Eight isolates of Didymella bryoniae from geographically diverse areas exhibit variation in virulence but no isolate by cultivar interaction on Cucumis sativus. Plant Dis. 79:11361139.

20. Zhang, Y., Kyle, M., Anagnostou, K., and Zitter, T. A. 1997. Screening melon (Cucumis melo) for resistance to gummy stem blight in the greenhouse and field. HortScience 32:117-121. 